but adding that Logothetis's scientific concerns should be taken into account, in accordance with the MPS's code of good scientific practice. Small changes were made to the paper that did not satisfy Logothetis, and it went online as planned on 8 May.

Jäckle says that the journal misrepresented his approval of the use of the data as being permission to publish. "But we only ever gave approval to use the data - the journal used the Max Planck Society to excuse their own mismanagement of the case."

Jäckle also notes that he requested that the MPS should not be listed in the paper as a funder of the project, because neither of the two authors had been directly funded by the society. But the request was ignored.

Logothetis says the paper does not give sufficient information to have allowed referees to understand the source of the data. He adds that Human Brain Mapping has not guaranteed him the opportunity to publish a response with his own interpretation of the data. He says the paper could mislead the field, for example, with its claims to see waves of activity in the cortex that Logothetis's analysis does not support.

Fox, who refused to retract the paper, says: "The editors of Human Brain Mapping were entirely appropriate - that's all I want to say about it."

Shmuel and Leopard issued a statement to Nature in which they say: "We are confident, and rigorous peer review agreed, that the data we collected are appropriate for studying spontaneous activity and the resting state in the brain. We stand by the conclusions we made in our paper."

Alison Abbott

Sengör has also spoken out publicly against YÖK's newly appointed president, Yusuf Ziya Özcan, a US-trained sociologist. In the Turkish press he has stated that Özcan is not qualified to be an assistant professor, let alone head of Turkey's higher-education council. "I simply said that this man is incompetent," Sengör says.

Such blunt statements have probably not endeared him to YÖK's leadership, says Șevket Ruacan, former head of Tübitak, Turkey's national science research agency. Nevertheless, Ruacan says that the inter-university board's nomination should be respected. "The president has no option but to appoint Celâl," he says.

Özcan declined Nature's request for an interview.

Geoff Brumfiel

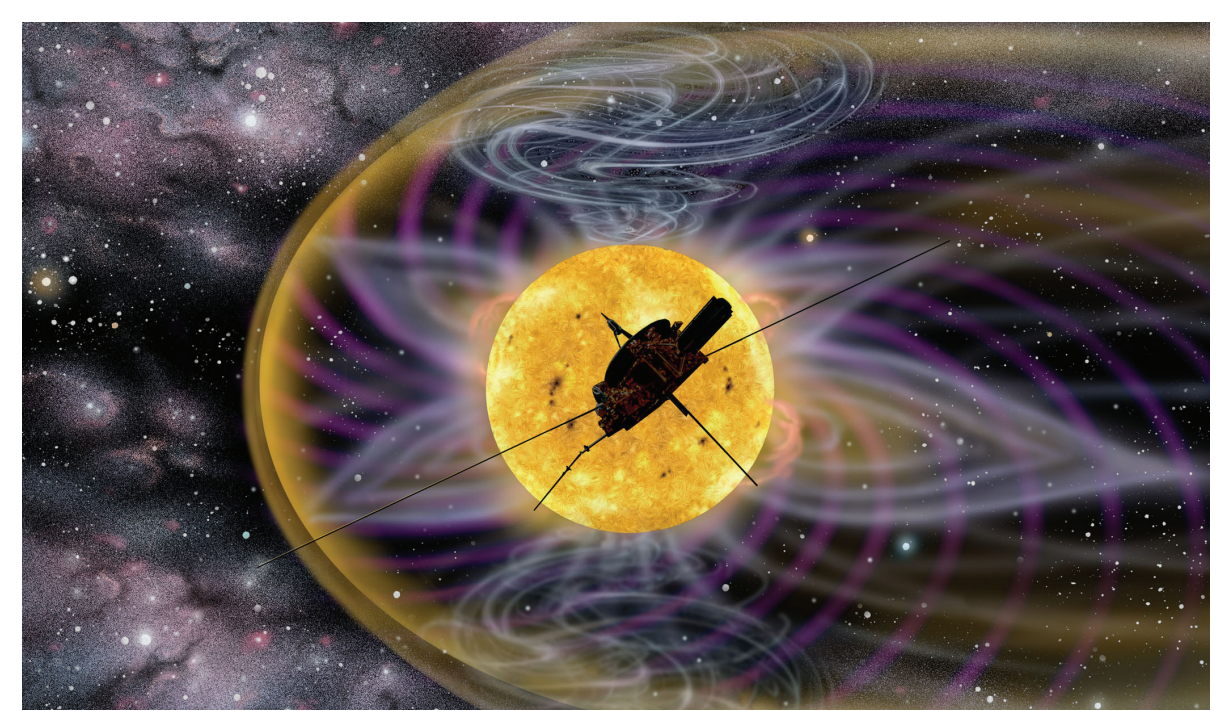

\title{
Closer than ever to the Sun
}

As the Voyager missions carry the hopes and dreams of Earthlings to the edge of the Solar System (see page 24), work is beginning on a major new mission to explore the superstar at its heart.

But scientists must first say goodbye to its predecessor Ulysses, the longest-serving spacecraft, which has swooped past the Sun's poles three times on its unique orbit out of the elliptic plane of the Solar System. Ulysses has been a joint project between the European Space Agency, which built the spacecraft, and NASA, which provided the launch rocket and a plutonium-238powered energy source. Its main goal was to map the heliosphere, the Sun's bubble of influence created by a stream of charged particles called the solar wind - which, for instance, 'blows' a comet's ion tail so that it always points away from the Sun. Ulysses passed through several comet-tails and measured the solar wind at periodic lows and highs, revealing that the wind is quite variable in time and space. Ulysses also discovered that the Sun's magnetic field has a strange asymmetry between its north and south poles.

But after nearly 18 years, the mission's odyssey is over. The fuel line could freeze shut in days, according to Ed Massey, NASA project manager at the Jet Propulsion Laboratory in Pasadena, California. There is no Ithaca for this Ulysses - once the fuel line freezes, engineers won't be able to orient the spacecraft's radio antennas towards Earth. It will continue to loop blindly around the

- Sun until at least 435 years from now, when a close pass of Jupiter could alter its course.
While Ulysses gasps its last, another NASA mission, Solar Probe Plus, is in initial development at the Applied Physics Laboratory in Laurel, Maryland. Solar Probe Plus would get closer to the Sun than any mission before in order to address two mysteries: why is the corona - the wispy, million-degree part of the Sun's atmosphere that can be seen during eclipses - so much hotter than the 6,000-degree surface of the Sun? And how, in this region, is the solar wind accelerated to supersonic speeds?

Protected by a carbon-foam shield 2.7 metres in diameter, Solar Probe Plus would tiptoe to the edge of the corona, passing at its closest within 6 million kilometres of the Sun's surface - about 10 times closer than Mercury.

For a solar mission, Ulysses never really got all that close. In fact, it was at its closest when it launched from Earth. And so it measured the effect of the Sun on the solar wind, rather than getting to the roots of its cause. "It's like trying to understand hurricanes without incorporating oceans in the model," says Andrew Dantzler, the project manager for Solar Probe Plus.

The US Congress specifically funded $\$ 14$ million in 2008 towards missiontechnology development, but NASA did not request any money for it in 2009 . The agency plans to ramp up mission funding, spending \$220 million by 2013 towards a tentative 2015 launch. But budget outlooks are still well short of the spacecraft's proposed \$900-million overall cost. Eric Hand 